\title{
Analysis of petrophysical cutoffs of reservoir intervals with production capacity and with accumulation capacity in clastic reservoirs
}

\author{
Wang Yanzhong ${ }^{1 *}$, Cao Yingchang ${ }^{1}$, Song Guoqi ${ }^{2}$, Song Ling ${ }^{3}$, Yang Tian ${ }^{1}$ \\ and Zhang Shaomin ${ }^{1}$ \\ ${ }^{1}$ School of Geosciences, China University of Petroleum, Shandong 266580, China \\ ${ }^{2}$ Geological Science Research Institute, Shengli Oilfield, SINOPEC, Shandong 257015, China \\ ${ }^{3}$ Western New Prospect Research Center of Shengli Oilfield, SINOPEC, Shandong 257015, China \\ (C) China University of Petroleum (Beijing) and Springer-Verlag Berlin Heidelberg 2014
}

\begin{abstract}
Methodologies have been developed for calculating cutoffs of reservoir intervals with production capacity (RIPC) and reservoir intervals with accumulation capacity (RIAC) according to the types of pore throat structures and dynamic force by using data from petrophysical analysis, production tests and mercury injection. The data are from clastic reservoirs in the third member $\left(\mathrm{Es}_{3}\right)$ and the fourth member $\left(\mathrm{Es}_{4}\right)$ of the Shahejie Formation in the Shengtuo area on the North Slope of the Dongying Sag, Jiyang Depression, China. The method of calculating cutoffs of RIPC is summarized as follows: 1) determination of permeability cutoffs of RIPC; 2) classification of types of pore-throat structures according to mercury injection data and then relating porosity to permeability and determining the relationship between porosity and permeability according to each type of pore-throat structure; and 3) calculating porosity cutoffs of RIPC using established correlation between porosity and permeability according to the type of pore throat structure. The method of calculating cutoffs of RIAC includes: 1) establishing a functional relationship between oil-water interfacial tension and formation temperature; 2) calculating limiting values of maximum connected pore-throat radii according to formation temperature and dynamic forces of each reservoir interval; 3) correlating permeability with maximum connected pore-throat radius and then obtaining permeability cutoffs of RIAC; and 4) calculating porosity cutoffs on the basis of permeability cutoffs according to specific correlations, suitable for the type of porethroat structure. The results of this study show that porosity and permeability cutoffs of clastic reservoirs decrease with depth. For a fixed permeability cutoff, the porosity cutoff of RIPC varies because the type of pore throat is different. At a fixed temperature, porosity and permeability cutoffs of RIAC decrease as dynamic force increases. For a fixed permeability cutoff of effective hydrocarbon accumulation, the porosity cutoff also varies with different types of pore throat.
\end{abstract}

Key words: Effective reservoir, petrophysical cutoff of reservoir intervals with production capacity (RIPC), petrophysical cutoff of reservoir intervals with accumulation capacity (RIAC), clastic rocks

\section{Introduction}

Exploration has focused on shallow depths in the Dongying Sag has been for many years, but the potential of significant discovery in shallow strata is decreasing. As a result, middle-to-deep formations have gradually become important targets for hydrocarbon exploration. However, middle-to-deep reservoirs have experienced complex reservoir reconstruction during the burial process, which results in complexity of producible reservoir distribution and additionally leads to complexity of hydrocarbon distribution.

*Corresponding author. email: wangyanzhong1980@163.com Received February 28, 2013
Those complexities make exploration and development activities aiming at middle-to-deep hydrocarbon reservoirs very difficult and risky. For hydrocarbon exploration and production, porosity and permeability cutoffs of clastic reservoirs have double meanings. One is for calculation of petrophysical cutoffs of reservoir intervals with production capacity (RIPC) and the other one is for determining petrophysical cutoffs of reservoir intervals with accumulation capacity (RIAC) (Cao et al, 2009). Research on petrophysical cutoffs of RIPC is the key difficult point for determining the distribution of producible intervals in a reservoir; while research on cutoffs of RIAC provides basic knowledge about hydrocarbon distribution during the period of hydrocarbon accumulation (Wang et al, 2008). 
Petroleum engineering and geology literature have introduced many methods to define petrophysical cutoffs of effective reservoirs, and the data used in these methods are from different sources, such as production tests, empirical statistics, minimum effective pore-throat radius calculation, distribution function curve analysis, oilbearing occurrence analysis, irreducible water saturation tests, relative permeability analysis, drilling fluid invasion analysis, porosity-permeability intersection plotting, capacity simulation experiments, and comprehensive analysis (Hobson, 1954; Rockwood et al, 1957; Geng et al, 1999; Guo, 2004; Shao et al, 2008; Cao et al, 2009; Wang et al, 2009; Wang and Cao, 2010; Zhang et al, 2010; Wang et al, 2011; Bouffin and Jensen, 2010). However, these methods overlook the fact that there are differences between the cutoffs of RIPC and of RIAC. Most researchers only use those methods to calculate porosity and permeability cutoffs of RIPC, or to calculate porosity cutoffs first and then to determine permeability cutoffs by using simple correlation between porosity and permeability (Qi, 1989; Wang and Cao, 2010; Guo, 2004; Wang et al, 2003; Wang et al, 2011; Cao et al, 2009; Jiang et al, 2003; Tang, 2011; Shao et al, 2008; Jiao et al, 2009), but the influence of pore throat structure is never mentioned. Actually for a specific permeability cutoff, porosity cutoff varies with different pore throat structures. Even though many scholars admit that pore throat structure exerts important influence on petrophysical cutoffs of RIPC (Geng et al, 1999; Wang et al, 2007; Zhang et al, 2010; Li et al, 1998; Nelson, 2009; Nelson and Batzle, 2006; Liu et al, 2012), there are no equations which are suitable to choose the cutoffs of RIPC according to different types of pore throat structures. Furthermore, the difference between cutoffs of RIPC and cutoffs of RIAC has not been emphasized enough (Qi, 1989; Guo, 2004; Wang et al, 2003; Wang et al, 2011; Jiang et al, 2003; Tang, 2011; Shao et al, 2008; Jiao et al, 2009; Geng et al, 1999; Wang et al, 2007), which leads to insufficient effort in determining methods on how to define the cutoffs of RIAC and impedes the progress in knowledge acquisition. A few researchers acknowledge the difference between the cutoffs of RIPC and of RIAC, and have discussed the influence of hydrocarbon accumulation dynamics on petrophysical cutoffs (Pan et al, 2011; Zhang et al, 2008; Pang et al, 2012). However, they never mention in detail how to calculate the limiting values of porosity and permeability for hydrocarbon accumulation.

This study is based on reservoirs in $\mathrm{Es}_{3}$ and $\mathrm{Es}_{4}$ in the Shengtuo area on the North Slope of the Dongying Sag. The methodology of calculating cutoffs of RIPC and of RIAC on the basis of different pore throat structures is presented, which provides technical support and theoretical guidance for hydrocarbon exploration and production aimed at middle-todeep reservoirs.

\section{Porosity and permeability cutoffs of RIPC in clastics}

\subsection{Methodology}

The cutoff of reservoir interval with production capacity
(RIPC) refers to limiting values of porosity and permeability in reservoirs that allow liquid to flow and accumulate, at same time, accumulated liquids (hydrocarbon or mixture of water and hydrocarbon) can be produced economically using contemporary technology. Under current techno-economic conditions, production is determined by permeability, pressure differential of petroleum production, reservoir thickness and formation fluid properties (Worthington and Cosentino, 2005; Worthington, 2008; MacKenzie, 1975; Hall, 1983; Cobb and Marek, 1998). Permeability is usually used to represent the ability of a reservoir to allow liquid to flow; while porosity measures the storage ability of a reservoir. But porosity does not represent flow characteristics of hydrocarbons in a reservoir. Therefore, when other conditions, such as pressure gradient, reservoir thickness and fluid physical properties, remain constant, the cutoff of RIPC in a reservoir would be a constant value. For a given permeability value, porosity varies depending on the type of pore throat structures. We can determine porosity cutoffs using different correlations between porosity and permeability according to the type of pore throat structure. So we can qualify the petrophysical cutoffs of a reservoir by steps as following:

1) According to availability of various data in an area, pick a reasonable method of calculating the permeability cutoffs of RIPC among existing methodologies (such as methods using data derived from minimum effective pore-throat radius, production tests, distribution function curve, and irreducible water saturation), and then estimate the permeability limiting value of RIPC. Then correlate producible permeability cutoffs of different reservoir intervals with depth. Using the correlation between permeability and depth, we can determine the producible permeability cutoff at a given depth.

2) Classify pore throat structures according to the parameters of displacement pressure $\left(P_{\mathrm{d}}\right)$ and median capillary pressure $\left(P_{50}\right)$ from mercury data. On the basis of the classification of pore structures, establish correlations between $K$ and $K / \Phi$ ( $K$ : permeability; $\Phi$ : porosity) according to different types of pore throat structures, and then determine the variation ranges of $K$ and $K / \Phi$ of different pore throat structure types.

3 ) According to the variation ranges of $K$ and $K / \Phi$ for a type of pore throat structure, fitting the permeability cutoff into the correlation between $K$ and $K / \Phi$, we can get the porosity cutoff of this type of pore throat structure, and then establish the relationship between porosity cutoffs and depth.

\subsection{Case study}

\subsubsection{Geological backgrounds}

The Shengtuo area of the Dongying Sag, Jiyang Depression is located in the middle portion of the North Slope, which is steep and formed by arrays of faults. The area covers about $230 \mathrm{~km}^{2}$ with exploration potential, which is bounded to the north by the Chenjiazhuang Salient, south by the Middle Fault-anticline Belt, southwest by the Lijin Subsag, and southeast by the Minfeng Subsag (Gao et al, 2008). The Shengbei fault is the most prominent one in the Shengtuo area, which is nearly east-west trending, and south dipping with an arc shape in plan view. The Paleogene Shengbei fault controls the sedimentary 
system and hydrocarbon accumulation (Zhu et al, 2004). During the period of the deposition of $\mathrm{Es}_{3}$ and $\mathrm{Es}_{4}$, coarse clastic sedimentation, such as nearshore subaqueous fan, sublacustrine fan, and fan delta deposits, occurred in the Shengtuo area. The distribution of the effective reservoirs in $\mathrm{Es}_{3}$ and $\mathrm{Es}_{4}$ is very complex, and the study on petrophysical cutoffs of RIPC and RIAC is relatively insufficient.

\subsubsection{The qualification of cutoffs of RIPC}

We calculate permeability cutoffs of RIPC in $\mathrm{Es}_{3}$ and $\mathrm{Es}_{4}$ in the Shengtuo area using the available data from well testing, production tests, mercury injection and distribution function curves (Song, 2011) (Table 1). And we also correlated permeability cutoffs of RIPC with depth as follows:

$$
K_{\text {cutoff }}=212.17 \mathrm{e}^{-0.001741 H}, R^{2}=0.8607
$$

where, $K_{\text {cutoff }}$ represents the permeability cutoff of RIPC, $10^{-3} \mu \mathrm{m}^{2} ; H$ represents depth, $\mathrm{m}$. As a result, we get permeability cutoffs of RIPC at any depth using the above equation.

Table 1 Permeability cutoffs of RIPC in $\mathrm{Es}_{3}$ and $\mathrm{Es}_{4}$ in the Shengtuo area, Dongying Sag (Song, 2011)

\begin{tabular}{|c|c|c|c|c|}
\hline Methods & $\begin{array}{c}\text { Top depth, } \\
\mathrm{m}\end{array}$ & $\begin{array}{l}\text { Bottom } \\
\text { depth, } m\end{array}$ & $\begin{array}{l}\text { Medium } \\
\text { depth, } m\end{array}$ & $\begin{array}{l}\text { Permeability } \\
\text { cutoff, } 10^{-3} \mu \mathrm{m}^{2}\end{array}$ \\
\hline Well test & 3000 & 3400 & 3200 & 1 \\
\hline $\begin{array}{l}\text { Distribution } \\
\text { function curve }\end{array}$ & 2500 & 3000 & 2750 & 1.62 \\
\hline $\begin{array}{l}\text { Distribution } \\
\text { function curve }\end{array}$ & 3000 & 3500 & 3250 & 0.75 \\
\hline $\begin{array}{l}\text { Minimum effective } \\
\text { pore-throat radius }\end{array}$ & 2500 & 3200 & 2850 & 1.83 \\
\hline Production test & 2900 & 3100 & 3000 & 1 \\
\hline Production test & 3100 & 3300 & 3200 & 1 \\
\hline Production test & 3300 & 3500 & 3400 & 0.51 \\
\hline
\end{tabular}

\subsubsection{The characteristics of pore throat structure}

Using mercury injection data, we classify pore-throat structures according to the parameters of displacement pressure $\left(P_{\mathrm{d}}\right)$ and median capillary pressure $\left(P_{50}\right)$. Firstly, reservoirs are classified into six types according to displacement pressure $\left(P_{\mathrm{d}}\right)$, as $\mathrm{I}_{\mathrm{A}}\left(P_{\mathrm{d}} \leq 0.05 \mathrm{MPa}\right), \mathrm{I}_{\mathrm{B}}(0.05-$ $\left.0.1 \mathrm{MPa} P_{\mathrm{d}}\right), \mathrm{II}_{\mathrm{A}}\left(0.1-0.5 \mathrm{MPa} P_{\mathrm{d}}\right), \mathrm{II}_{\mathrm{B}}\left(0.5-2 \mathrm{MPa} P_{\mathrm{d}}\right), \mathrm{III}_{\mathrm{A}}$ (2-5 MPa $\left.P_{\mathrm{d}}\right), \operatorname{III}_{\mathrm{B}}\left(P_{\mathrm{d}}>5 \mathrm{MPa}\right)$. Secondly, each type is further divided into six units according to median capillary pressure $\left(P_{50}\right)$, as $P_{50} \leq 0.3 \mathrm{MPa}, 0.3-1.5 \mathrm{MPa} P_{50}, 1.5-5 \mathrm{MPa}$ $P_{50}, 5-20 \mathrm{MPa} P_{50}, 20-40 \mathrm{MPa} P_{50}, P_{50}>40 \mathrm{MPa}$. If $P_{50}$ datum is not in accordance with the overall characteristics of a unit, then assign the sample to the lower unit in Fig. 1. Then we divide reservoirs in $\mathrm{Es}_{3}$ and $\mathrm{Es}_{4}$ in the Shengtuo area into three mega-types and six types. Then we correlate $K / \Phi$ with $K$ for each type of reservoir (Fig. 2). So, we can determine the ranges of permeability and the ratio of permeability to porosity according to types of reservoir (Table 2).

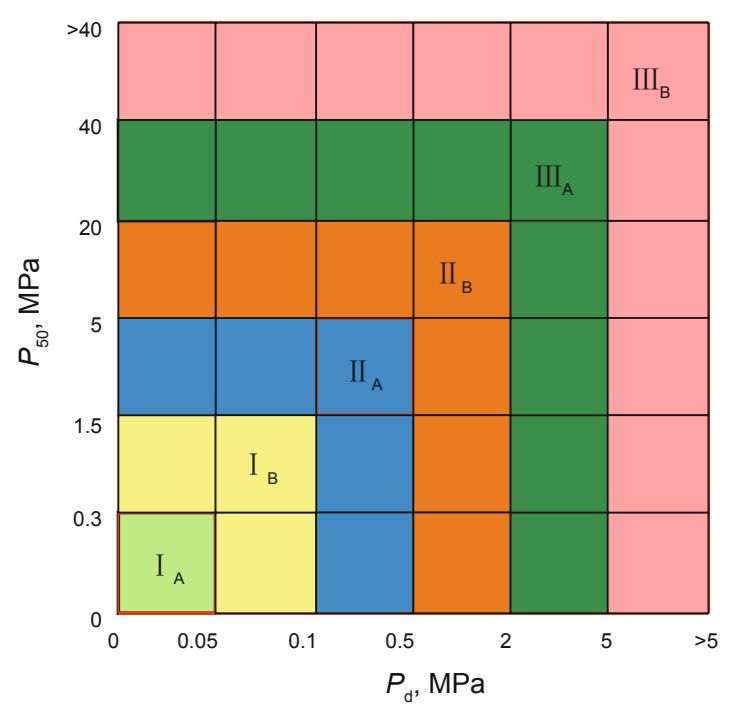

Fig. 1 Sketch map of types of pore-throat structures
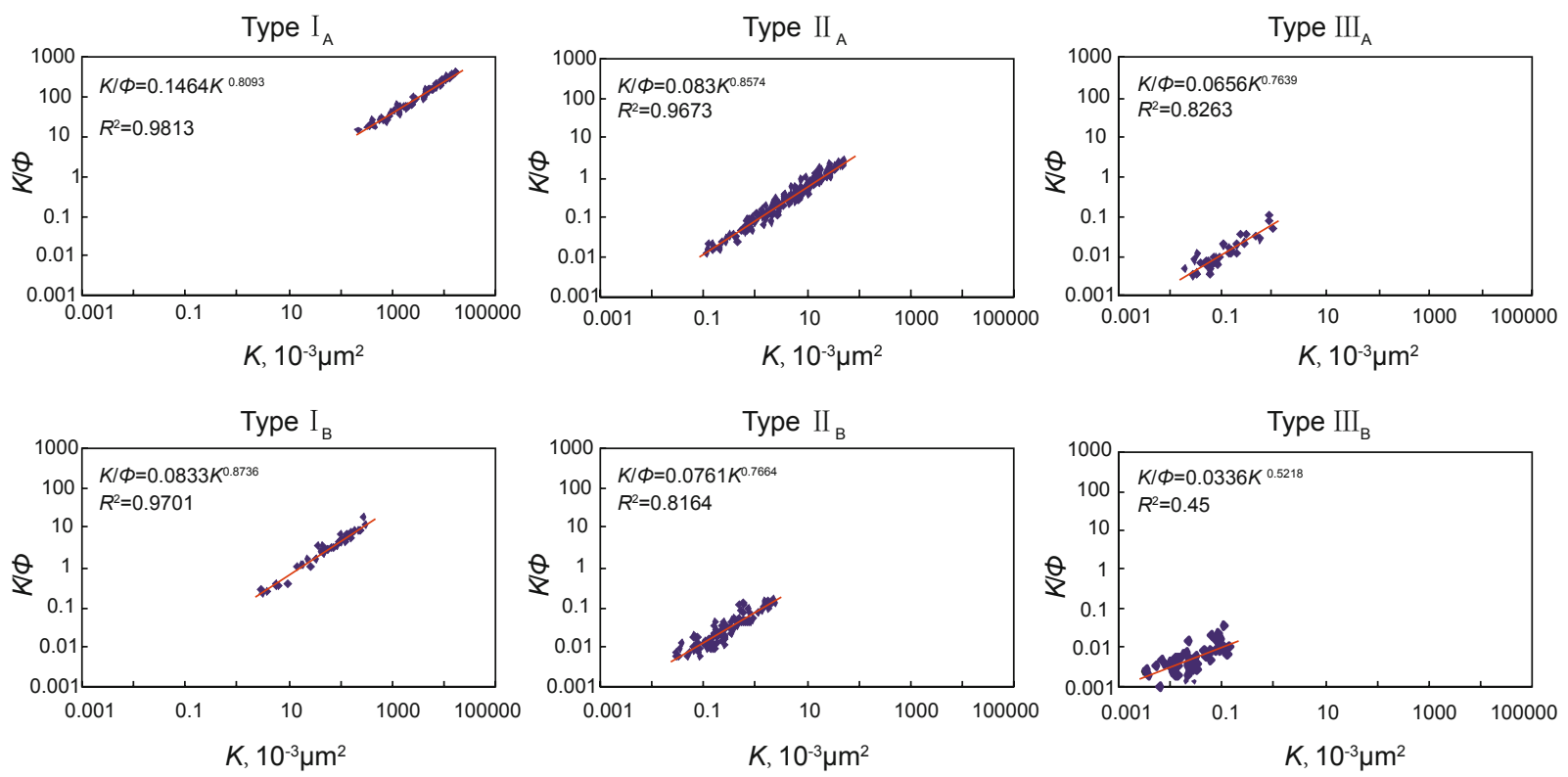

Fig. 2 Porosity-permeability relationships of each type of pore throat structure in $\mathrm{Es}_{3}$ and $\mathrm{Es}_{4}$ in the Shengtuo area 
Table 2 Varying ranges of $K$ and $K / \Phi$ according to each type of pore throat structure in $\mathrm{Es}_{3}$ and $\mathrm{Es}_{4}$ in the Shengtuo area

\begin{tabular}{ccc}
\hline Type of pore-throat structure & $K, 10^{-3} \mu \mathrm{m}^{2}$ & $K / \Phi$ \\
\hline $\mathrm{I}_{\mathrm{A}}$ & $>228$ & $>14.64$ \\
$\mathrm{I}_{\mathrm{B}}$ & $2.92-304$ & $0.218-18.077$ \\
$\mathrm{II}_{\mathrm{A}}$ & $0.1-50.48$ & $0.0123-2.723$ \\
$\mathrm{II}_{\mathrm{B}}$ & $0.0289-2.486$ & $0.0056-0.164$ \\
$\mathrm{III}_{\mathrm{A}}$ & $0.0181-0.97$ & $0.00337-0.109$ \\
$\mathrm{III}_{\mathrm{B}}$ & $<0.133$ & $<0.105$ \\
\hline
\end{tabular}

\subsubsection{Qualification of porosity cutoffs of RIPC for each} pore throat structure type

After calculation of permeability cutoff of RIPC at a given depth, we can get the corresponding porosity cutoff of RIPC by applying the permeability cutoff into the correlation of $K$ and $K / \Phi$ (Fig. 3). From Fig. 3, we can draw the conclusion that, for a fixed permeability at a depth, porosity cutoffs vary according to the type of pore throat structure.

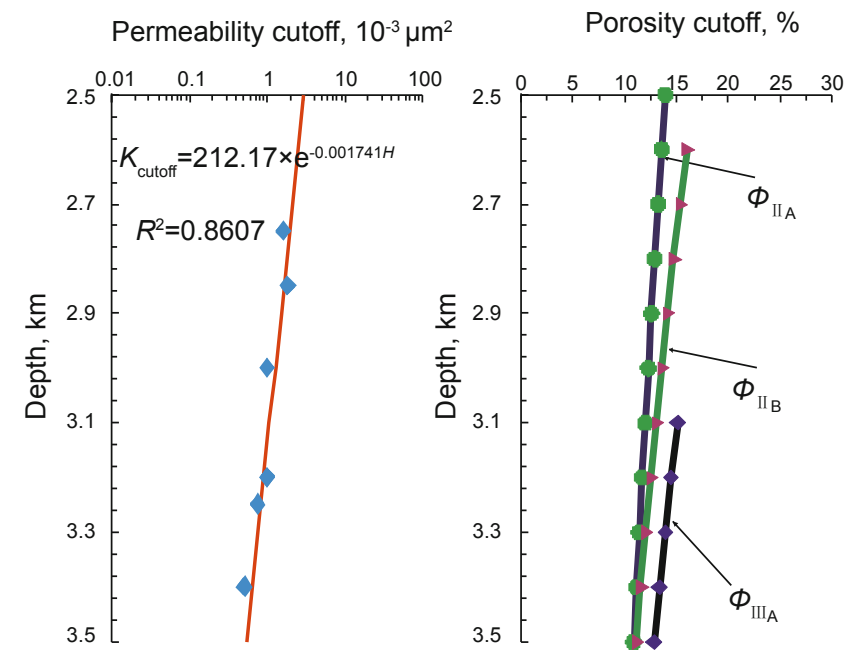

Fig. 3 Porosity and permeability cutoffs of RIPC in reservoirs in $\mathrm{Es}_{3}$ and $\mathrm{Es}_{4}$ according to the type of pore throat structure

\subsubsection{Validation of results}

In order to validate the method above, we take reservoir intervals ranging from $2.5 \mathrm{~km}$ to $3.5 \mathrm{~km}$ in $\mathrm{Es}_{3}$ and $\mathrm{Es}_{4}$ in the western Shengtuo area of the Dongying Sag as examples, and firstly calculate permeability cutoffs of RIPC at middle depth using available data, such as petrophysical measurements on cores, production data and mercury injection data. Then we calculate porosity cutoffs of RIPC for each type of pore throat structure. After that, we verify the results using data from 21 reservoir intervals (12 wells, Table 3 ). The principle of verification goes like this: if a reservoir interval is verified by production tests as an effective reservoir and both porosity and permeability of the reservoir interval are higher than the petrophysical cutoffs of RIPC, we consider the result as right. If a reservoir interval is verified as ineffective reservoir and either of the porosity and permeability is lower than the petrophysical cutoffs of RIPC, we also consider the result as right (Wang et al, 2008). Results show that about $90 \%$ of the results are correct. So we regard this method as reliable in calculating petrophysical cutoffs in clastics.

\section{Porosity and permeability cutoffs of RIAC}

\subsection{Methodology}

The petrophysical cutoff of reservoir interval with accumulation capacity (RIAC) refers to the limiting values of porosity and permeability in a reservoir, which is enough for petroleum to flow and accumulate during the period of petroleum migration under dynamic forces and with specific oil and water properties. It is mainly controlled by petroleum accumulation dynamic forces, fluid properties, formation pressure, and reservoir characteristics. Dynamic force is the most important factor for petroleum accumulation. Capillary pressure $\left(P_{\mathrm{c}}\right)$ is the most important resistance force in hydrophilic rocks. Only when the dynamic force surpasses the resistance force can petroleum seep into rocks and form petroleum reservoirs (Hao et al, 2010). So, considering reservoir forming dynamics, permeability cutoffs can first be calculated, and then we compute porosity cutoffs according to the correlations of permeability and porosity for different types of pore throat structure. As a result, we can calculate petrophysical cutoffs of RIAC as follows:

1) Correlate oil-water interfacial tension with temperature, and establish a functional relationship between oil-water interfacial tension and formation temperature.

The oil-water interfacial tension is mainly affected by the formation temperature and density contrast between oil and brine, and the functional relationship among them is (Danesh, 1998):

$$
\delta=111\left(\rho_{\mathrm{w}}-\rho_{\mathrm{h}}\right)^{1.024}\left(T / T_{\mathrm{c}}\right)^{-1.25}
$$

where, $\delta$ : oil-water interfacial tension, $\mathrm{mN} / \mathrm{m} ; \rho_{\mathrm{w}}$ : density of formation water, $\mathrm{g} / \mathrm{cm}^{3} ; \rho_{\mathrm{h}}$ : density of hydrocarbon, $\mathrm{g} /$ $\mathrm{cm}^{3} ; T$ : formation temperature, $\mathrm{K} ; T_{\mathrm{c}}$ : critical temperature of hydrocarbon, $\mathrm{K}$.

The densities of brine and hydrocarbon are affected by temperature and pressure, and the functional equation is (Luo and Vasseur, 1996):

$$
\rho=\rho_{\mathrm{f}} \mathrm{e}^{-\alpha\left(T-T_{\mathrm{o}}\right)+\beta\left(P-P_{\mathrm{o}}\right)}
$$

where, $\alpha$ : fluid thermal expansion coefficient; $\beta$ : fluid compressibility coefficient; $T_{\mathrm{o}}$ : reference temperature, ${ }^{\circ} \mathrm{C}$; $P_{\mathrm{o}}$ : reference pressure, $\mathrm{Pa} ; \rho_{\mathrm{f}}$ : fluid density at reference temperature and pressure.

According to Eq. (2), the density contrast between oil and brine at a given temperature and pressure can be obtained (Table 4).

Data in Table 4 show that density contrasts between oil and brine are extremely small at a fixed temperature with different given formation pressures. The largest density contrast is less than $0.13 \mathrm{~kg} / \mathrm{m}^{3}$. While at a fixed pressure, density contrasts between oil and brine are very great, with 
Table 3 Verification results of porosity and permeability cutoffs of RIPC in $\mathrm{Es}_{3}$ and $\mathrm{Es}_{4}$ in the Shengtuo area, Dongying Sag

\begin{tabular}{|c|c|c|c|c|c|c|c|c|c|c|c|c|c|}
\hline \multirow{2}{*}{ Well } & \multirow{2}{*}{$\begin{array}{l}\text { Middle } \\
\text { depth, } \mathrm{m}\end{array}$} & \multirow{2}{*}{$\begin{array}{c}\text { Production } \\
\text { test }\end{array}$} & \multirow{2}{*}{$\begin{array}{l}\text { Daily oil } \\
\text { production } \\
\mathrm{t}\end{array}$} & \multirow{2}{*}{$\begin{array}{c}\text { Daily water } \\
\text { production } \\
\mathrm{m}^{3}\end{array}$} & \multicolumn{2}{|c|}{$\begin{array}{l}\text { Average petrophysical } \\
\text { properties }\end{array}$} & \multirow{2}{*}{$\begin{array}{c}\text { Pore-throat } \\
\text { structure }\end{array}$} & \multicolumn{2}{|c|}{ Petrophysical property cutoff } & \multicolumn{2}{|c|}{ Distinguishing result } & \multirow{2}{*}{$\begin{array}{c}\text { Integrated } \\
\text { - distinguishing } \\
\text { result }\end{array}$} & \multirow{2}{*}{ Accuracy } \\
\hline & & & & & Porosity, \% & $\begin{array}{l}\text { Permeability } \\
\mathrm{mD}\end{array}$ & & Porosity, \% & $\begin{array}{c}\text { Permeability } \\
\mathrm{mD}\end{array}$ & Porosity & Permeability & & \\
\hline Tuo122 & 2936.95 & Oil layer & 14.1 & 0.057 & 10.3 & 2.3 & $\mathrm{II}_{\mathrm{A}}$ & 12.43 & 0.94 & wrong & right & wrong & \\
\hline Tuo126 & 2842.7 & Dry layer & 0.21 & 0 & 10.6 & 5.9 & $I_{B}$ & 11.49 & 1.16 & right & wrong & right & \\
\hline Tuo128 & 2603 & Oil layer & 7.82 & 0 & 14.58 & 11.67 & $\mathrm{I}_{\mathrm{B}}$ & 12.34 & 1.96 & right & right & right & \\
\hline Tuo145 & 2052.7 & Oil layer & 21.94 & 0 & 17.9 & 30.1 & $\mathrm{I}_{\mathrm{B}}$ & 14.56 & 6.57 & right & right & right & \\
\hline Tuo157 & 2847.45 & Dry layer & 0.64 & 0 & 5.7 & 1.9 & $\mathrm{II}_{\mathrm{A}}$ & 12.77 & 1.14 & right & wrong & right & \\
\hline Tuo174 & 2886.7 & Dry layer & 0.37 & 0 & 4.6 & 0.25 & $\mathrm{II}_{\mathrm{B}}$ & 13.83 & 1.05 & right & right & right & \\
\hline Tuo174 & 2956.1 & Dry layer & 0.09 & 0 & 4.5 & 0.3 & $\mathrm{II}_{\mathrm{B}}$ & 13.36 & 0.90 & right & right & right & \\
\hline Yan22 & 3217.5 & $\begin{array}{l}\text { Oil-water } \\
\text { layer }\end{array}$ & 12.6 & 0.19 & 12.1 & 7.2 & $\mathrm{I}_{\mathrm{B}}$ & 10.27 & 0.51 & right & right & right & \\
\hline Yan22 & 3240.75 & Oil layer & 9.46 & 0.163 & 11.6 & 5.35 & $\mathrm{I}_{\mathrm{B}}$ & 10.19 & 0.48 & right & right & right & \\
\hline Yong92 & 2847.2 & $\begin{array}{l}\text { Oil-bearing } \\
\text { water layer }\end{array}$ & 0.002 & 0 & 11.1 & 4.2 & $\mathrm{I}_{\mathrm{B}}$ & 11.47 & 1.14 & wrong & right & wrong & \\
\hline Yong92 & 2951.9 & $\begin{array}{l}\text { Oil-bearing } \\
\text { water layer }\end{array}$ & 0.002 & 0 & 12.4 & 10.8 & $\mathrm{I}_{\mathrm{B}}$ & 11.12 & 0.91 & right & right & right & $90.48 \%$ \\
\hline Yong92 & 2957.6 & $\begin{array}{l}\text { Oil-bearing } \\
\text { water layer }\end{array}$ & 0.002 & 0 & 12.1 & 10.6 & $\mathrm{I}_{\mathrm{B}}$ & 11.10 & 0.90 & right & right & right & \\
\hline Yong920 & 3305 & Dry layer & 0 & 0 & 6.7 & 1.4 & $\mathrm{II}_{\mathrm{A}}$ & 11.13 & 0.42 & right & wrong & right & \\
\hline Yong920 & 3438.4 & Dry layer & 0 & 0 & 5.6 & 0.7 & $\mathrm{II}_{\mathrm{A}}$ & 10.70 & 0.31 & right & wrong & right & \\
\hline Yong921 & 2792.5 & Oil layer & 13.6 & 0 & 15.7 & 16.1 & $\mathrm{I}_{\mathrm{B}}$ & 11.66 & 1.29 & right & right & right & \\
\hline Yong921 & 2856.7 & Oil layer & 14 & 0 & 13.8 & 6.3 & $\mathrm{I}_{\mathrm{B}}$ & 11.44 & 1.12 & right & right & right & \\
\hline Yong922 & 2778.6 & $\begin{array}{c}\text { Oil-water } \\
\text { layer }\end{array}$ & 9.02 & 0 & 18.9 & 31.4 & $\mathrm{I}_{\mathrm{B}}$ & 11.71 & 1.33 & right & right & right & \\
\hline Yong922 & 2827.5 & $\begin{array}{l}\text { Oil-water } \\
\text { layer }\end{array}$ & 7.35 & 0 & 13.3 & 4.9 & $\mathrm{I}_{\mathrm{B}}$ & 11.54 & 1.19 & right & right & right & \\
\hline Yong922 & 2875.8 & Oil layer & 6.76 & 0 & 15.9 & 12.8 & $\mathrm{I}_{\mathrm{B}}$ & 11.37 & 1.07 & right & right & right & \\
\hline Yong924 & 2762.3 & Oil layer & 4.37 & 0 & 13.1 & 7.3 & $\mathrm{I}_{\mathrm{B}}$ & 11.77 & 1.38 & right & right & right & \\
\hline Yong924 & 2909.2 & Water layer & 0.14 & 0 & 12.6 & 7 & $\mathrm{I}_{\mathrm{B}}$ & 11.26 & 1.00 & right & right & right & \\
\hline
\end{tabular}

Table 4 Density contrasts between oil and brine under different temperatures and pressures

\begin{tabular}{cccccccc}
\hline & \multicolumn{9}{c}{ Density contrast at different system pressures (MPa), $\mathrm{kg} / \mathrm{m}^{3}$} & Maximum difference \\
\cline { 2 - 7 } System temperature, ${ }^{\circ} \mathrm{C}$ & 10 & 20 & 30 & 40 & 50 & 60 & 0.13 \\
\hline 50 & 173.42 & 173.46 & 173.49 & 173.52 & 173.54 & 173.56 & 0.12 \\
70 & 170.61 & 170.65 & 170.68 & 170.70 & 170.72 & 170.74 & 0.11 \\
90 & 167.85 & 167.88 & 167.91 & 167.93 & 167.95 & 167.96 & 0.10 \\
110 & 165.14 & 165.17 & 165.19 & 165.21 & 165.23 & 165.24 & 0.09 \\
130 & 162.46 & 162.49 & 162.51 & 162.53 & 162.54 & 162.55 & 0.08 \\
\hline 150 & 159.83 & 159.86 & 159.88 & 159.89 & 159.90 & 159.91 & \\
\hline Maximum difference, $\mathrm{kg} / \mathrm{m}^{3}$ & 10.78 & 10.79 & 10.80 & 10.81 & 10.82 & 10.83 & \\
\hline
\end{tabular}

an average value of $10.8 \mathrm{~kg} / \mathrm{m}^{3}$, with different formation temperatures. Therefore, density contrast between oil and brine is mainly controlled by formation temperature, and the influence of pressure on fluid density contrast is negligible. Thus, from Eq. (1) and Eq. (2), we can conclude that oil-water interfacial tension $(\delta)$ is a function of formation temperature. The functional relationship can be correlated using oil-water interfacial tension data at different temperatures in the study area.

$$
\delta=f(T)
$$

2) The capillary pressure of clastic reservoirs $\left(P_{c}=2 \delta \cos \theta /\right.$ $r_{0}$, where $P_{\mathrm{c}}$ : capillary pressure, MPa; $r_{0}$ : the maximum connected pore-throat radius, $\mu \mathrm{m} ; \delta$ : oil-water interfacial tension, $\mathrm{N} / \mathrm{m} ; \theta$ : wetting contact angle of oil-water to rock, $30^{\circ}$ ) mainly depends on the radius of the largest connected pore throats in clastic reservoirs when oil-water interfacial tension and wetting contact angle of oil-water to rock $\left(\theta=30^{\circ}\right)$ 
are known. Therefore, using the function and capillary pressure under the critical state of petroleum accumulation, where the driving force equals the resistance force or capillary pressure (Xie and Jin, 2008), we can get the cutoffs of the largest connected pore-throat radius of clastic reservoirs during the period of petroleum accumulation by equation $r_{0}=2 \delta \cos \theta / P_{\mathrm{f}}$.

3) Then the functional relationship between the maximum connected pore-throat radius and permeability can be established using mercury injection data. After that, the permeability cutoffs of RIAC in clastic reservoirs can be obtained at different formation temperatures and petroleum accumulation dynamic forces.

4) Classify pore-throat structures into several types according to displacement pressure $\left(P_{\mathrm{d}}\right)$ and median capillary pressure $\left(P_{50}\right)$. On the basis of this classification, establish functional relationships between $K / \Phi$ and $K$, as well as corresponding variation ranges of $K / \Phi$ and $K$ for each type of pore throat structure.

5) Put permeability cutoffs of RIAC back into the correlation between $K / \Phi$ and $K$ of the corresponding type of pore-throat structure under different formation temperatures and petroleum accumulation dynamic conditions, and porosity cutoffs of RIAC of different pore-throat structures can be obtained.

\subsection{Case study}

We used the reservoirs in $\mathrm{Es}_{3}$ and $\mathrm{Es}_{4}$ in the Shengtuo area on the North Slope in the Dongying Sag as examples. Their RIAC porosity and permeability cutoffs have been calculated according to accumulation dynamics and porethroat structures.

\subsubsection{Calculation of oil-water interfacial tension}

We correlated oil-water interfacial tension $(\delta)$ with formation temperature $(T)$ according to testing data in $\mathrm{Es}_{3}$ and $\mathrm{Es}_{4}$ (Fig. 4). Then we determined the oil-water interfacial value for a given temperature. For example, at $50^{\circ} \mathrm{C}$, the corresponding interfacial tension can be calculated to be 22.6 $\mathrm{mN} / \mathrm{m}$ according to Fig. 4.

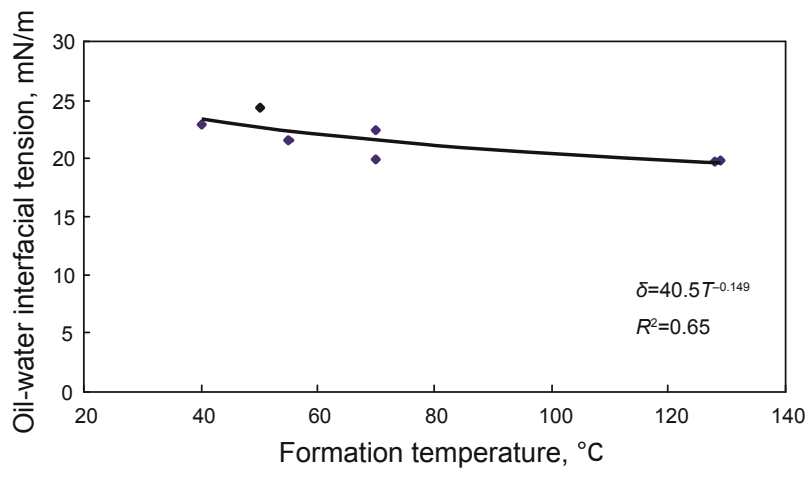

Fig. 4 Relationship between oil-water interfacial tension $(\delta)$ and formation temperature $(T)$ in $\mathrm{Es}_{3}$ and $\mathrm{Es}_{4}$ in the Shengtuo area

\subsubsection{Cutoffs of maximum connected pore-throat radius from petroleum accumulation dynamics}

For a fixed critical accumulation dynamic value $P_{\mathrm{f}}$, we can get cutoffs of maximum connected pore throat radius through equation $r_{0}=2 \delta \cos \theta / P_{\mathrm{f}}$ by using $30^{\circ}$ wetting contact angle of oil-water and $22.6 \mathrm{mN} / \mathrm{m}$ interfacial tension at $50^{\circ} \mathrm{C}$ (Table 5).

\subsubsection{The calculation of permeability cutoffs of RIAC}

Establishing a correlation between permeability and maximum connected pore-throat radius using mercury injection data (Fig. 5), we find that there is a good exponential relationship between permeability and the maximum connected pore-throat radius as:

$$
K=0.4344 \times r_{0}^{1.933}, R^{2}=0.881
$$

where, $K$ : permeability, $10^{-3} \mu \mathrm{m}^{2} ; r_{0}$ : maximum connected pore-throat radius, $\mu \mathrm{m}$.

Put the limiting value of the maximum connected porethroat radius with different critical accumulation dynamics into Eq. (4), and a series of permeability cutoffs of RIAC can be obtained at $50^{\circ} \mathrm{C}$ (Table 5).

\subsubsection{Calculation of porosity cutoffs of RIAC according to} different pore-throat structures

On the basis of the classification of pore-throat structures and the determination of functional relationships between $K$ and $K / \Phi$ of different pore-throat structures as well as their variation ranges (Fig. 2, Table 2), porosity cutoffs can be calculated by putting permeability cutoffs back into the established equation between $K$ and $K / \Phi$ according to proposed six pore-throat structure types in Fig. 3. We calculate porosity cutoffs according to variation ranges of permeability in Table 2 and regard those cutoffs as porosity cutoffs of RIAC for the corresponding type of pore-throat structure under different critical accumulation dynamics (Fig. 6 , Table 5). In this way, permeability and porosity cutoffs of RIAC under the constraints of different accumulation dynamics and pore-throat structures can be ultimately obtained.

\subsubsection{Discussion on reliability of porosity and permeability cutoffs of RIAC}

A series of key issues, such as calculating petroleum accumulation dynamics and reservoir petrophysical properties at the period of petroleum accumulation, are involved in the verification of the accuracy of the results using this method. Reservoirs have generally experienced complicated diagenesis during the burial process for middledeep formations, so it is very difficult to determine the variation of reservoir petrophysical properties in geological history. Petroleum accumulation dynamics is a synthesis of petroleum generation, expulsion, migration, enrichment and accumulation. As a result, there are still many problems remaining when it comes to calculating dynamic forces in the process of petroleum accumulation (Luo, 2008). Therefore, there is still no reliable method to verify the accuracy of this method.

\section{Conclusions}

1) A methodology of calculating porosity and permeability cutoffs of RIPC for different pore-throat structures has been developed. This makes the determination of the porosity limiting value in petroleum exploitation more accurate, so 
Table 5 Permeability and porosity cutoffs of RIAC with different accumulation dynamics and with different pore-throat structures at $50^{\circ} \mathrm{C}$ in $\mathrm{Es}_{3}$ and $\mathrm{Es}_{4}$, Shengtuo area

\begin{tabular}{|c|c|c|c|c|c|c|c|c|}
\hline \multicolumn{9}{|c|}{ Permeability and porosity cutoffs of RIAC at $50^{\circ} \mathrm{C}$} \\
\hline \multirow{2}{*}{$\begin{array}{l}\text { Accumulation dynamic } \\
\qquad P_{\mathrm{f}}, \mathrm{MPa}\end{array}$} & \multirow{2}{*}{$\begin{array}{c}\text { Maximum connected } \\
\text { pore-throat radius } \\
r_{\mathrm{o}}, \mu \mathrm{m}\end{array}$} & \multirow{2}{*}{$\begin{array}{c}K_{\text {cutoff }} \\
10^{-3} \mu \mathrm{m}^{2}\end{array}$} & \multicolumn{6}{|c|}{$\Phi_{\text {cutoff }}, \%$} \\
\hline & & & $\Phi_{\mathrm{I}_{\mathrm{A}}}$ & $\Phi_{\mathrm{I}_{\mathrm{B}}}$ & $\Phi_{\mathrm{II}_{\mathrm{A}}}$ & $\Phi_{\mathrm{II}_{\mathrm{B}}}$ & $\Phi_{\mathrm{III}_{\mathrm{A}}}$ & $\Phi_{\mathrm{III}_{\mathrm{I}}}$ \\
\hline 0.01 & 62.885 & 1301.619 & 26.82 & - & - & - & - & - \\
\hline 0.02 & 31.443 & 340.873 & 20.77 & - & - & - & - & - \\
\hline 0.022 & 28.584 & 283.518 & 20.05 & 24.51 & - & - & - & - \\
\hline 0.024 & 26.202 & 239.627 & 19.42 & 24.00 & - & - & - & - \\
\hline 0.026 & 24.187 & 205.227 & - & 23.53 & - & - & - & - \\
\hline 0.028 & 22.459 & 177.880 & - & 23.11 & - & - & - & - \\
\hline 0.03 & 20.962 & 155.671 & - & 22.72 & - & - & - & - \\
\hline 0.035 & 17.967 & 115.558 & - & 21.88 & - & - & - & - \\
\hline 0.04 & 15.721 & 89.269 & - & 21.18 & - & - & - & - \\
\hline 0.045 & 13.974 & 71.093 & - & 20.58 & - & - & - & - \\
\hline 0.05 & 12.577 & 57.993 & - & 20.06 & - & - & - & - \\
\hline 0.055 & 11.434 & 48.235 & - & 19.59 & 20.94 & - & - & - \\
\hline 0.06 & 10.481 & 40.768 & - & 19.18 & 20.44 & - & - & - \\
\hline 0.07 & 8.984 & 30.263 & - & 18.47 & 19.59 & - & - & - \\
\hline 0.08 & 7.861 & 23.378 & - & 17.88 & 18.88 & - & - & - \\
\hline 0.09 & 6.987 & 18.618 & - & 17.37 & 18.28 & - & - & - \\
\hline 0.1 & 6.289 & 15.187 & - & 16.93 & 17.76 & - & - & - \\
\hline 0.12 & 5.240 & 10.676 & - & 16.19 & 16.89 & - & - & - \\
\hline 0.137 & 4.590 & 8.264 & - & 15.68 & 16.28 & - & - & - \\
\hline 0.14 & 4.492 & 7.925 & - & 15.60 & 16.19 & - & - & - \\
\hline 0.16 & 3.930 & 6.122 & - & 15.09 & 15.60 & - & - & - \\
\hline 0.18 & 3.494 & 4.876 & - & 14.67 & 15.10 & - & - & - \\
\hline 0.2 & 3.144 & 3.977 & - & 14.29 & 14.67 & - & - & - \\
\hline 0.3 & 2.096 & 1.816 & - & - & 13.12 & 15.11 & - & - \\
\hline 0.4 & 1.572 & 1.042 & - & - & 12.12 & 13.27 & - & - \\
\hline 0.5 & 1.258 & 0.677 & - & - & 11.40 & 11.99 & 13.90 & - \\
\hline 0.6 & 1.048 & 0.476 & - & - & 10.84 & 11.05 & 12.79 & - \\
\hline 0.7 & 0.898 & 0.353 & - & - & 10.39 & 10.30 & 11.92 & - \\
\hline 0.8 & 0.786 & 0.273 & - & - & 10.01 & 9.70 & 11.22 & - \\
\hline 0.9 & 0.699 & 0.217 & - & - & 9.69 & 9.20 & 10.63 & - \\
\hline 1 & 0.629 & 0.177 & - & - & 9.41 & 8.77 & 10.13 & - \\
\hline 1.2 & 0.524 & 0.125 & - & - & 8.95 & 8.08 & 9.32 & 10.95 \\
\hline 1.4 & 0.449 & 0.092 & - & - & 8.58 & 7.53 & 8.69 & 9.53 \\
\hline 1.5 & 0.419 & 0.081 & - & - & 8.42 & 7.30 & 8.42 & 8.94 \\
\hline 1.6 & 0.393 & 0.071 & - & - & - & 7.09 & 8.18 & 8.43 \\
\hline 1.8 & 0.349 & 0.057 & - & - & - & 6.73 & 7.75 & 7.56 \\
\hline 1.9 & 0.331 & 0.051 & - & - & - & 6.56 & 7.56 & 7.19 \\
\hline 2 & 0.314 & 0.046 & - & - & - & 6.41 & 7.38 & 6.86 \\
\hline 2.1 & 0.299 & 0.042 & - & - & - & 6.27 & 7.22 & 6.55 \\
\hline 2.2 & 0.286 & 0.039 & - & - & - & 6.14 & 7.07 & 6.28 \\
\hline 2.4 & 0.262 & 0.033 & - & - & - & 5.91 & 6.79 & 5.79 \\
\hline 2.5 & 0.252 & 0.030 & - & - & - & 5.80 & 6.67 & 5.58 \\
\hline 3 & 0.210 & 0.021 & - & - & - & - & 6.14 & 4.71 \\
\hline 3.2 & 0.197 & 0.019 & - & - & - & - & 5.96 & 4.44 \\
\hline 3.4 & 0.185 & 0.017 & - & - & - & - & - & 4.20 \\
\hline 3.5 & 0.180 & 0.016 & - & - & - & - & - & 4.09 \\
\hline 3.6 & 0.175 & 0.015 & - & - & - & - & - & 3.98 \\
\hline 4 & 0.157 & 0.012 & - & - & - & - & - & 3.61 \\
\hline 6 & 0.105 & 0.006 & - & - & - & - & - & 2.48 \\
\hline 8 & 0.079 & 0.003 & - & - & - & - & - & 1.90 \\
\hline 10 & 0.063 & 0.002 & - & - & - & - & - & 1.55 \\
\hline
\end{tabular}




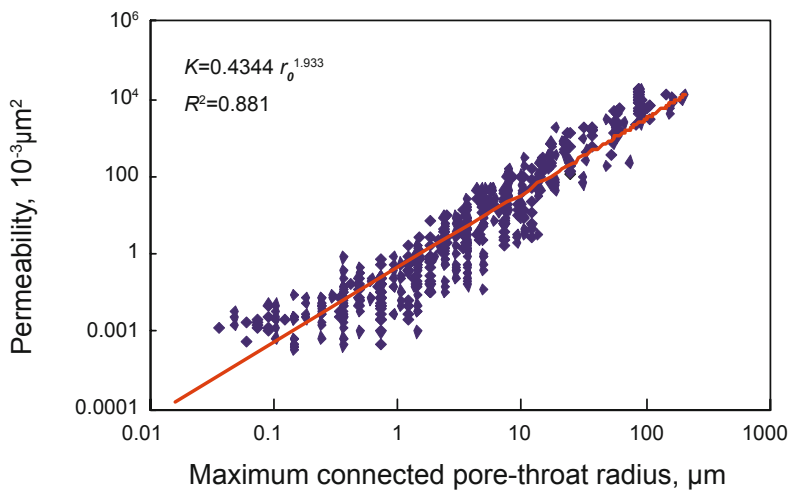

Fig. 5 Permeability versus maximum connected pore-throat radius of clastic reservoirs in $\mathrm{Es}_{3}$ and $\mathrm{Es}_{4}$, Shengtuo area

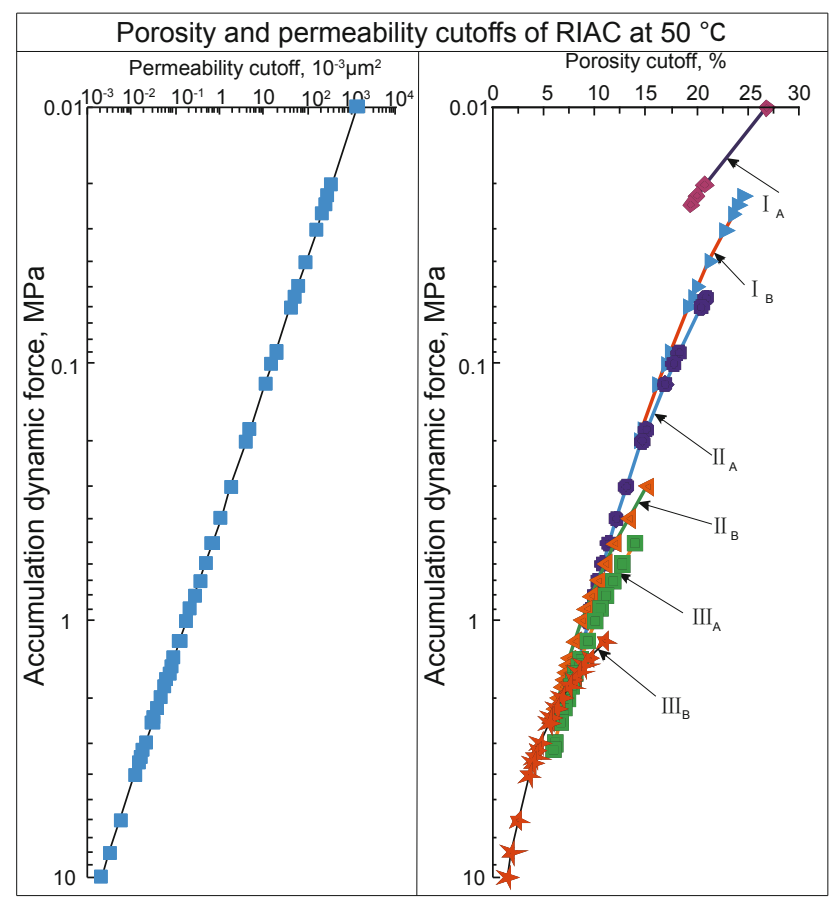

Fig. 6 Porosity and permeability cutoffs of RIAC at $50^{\circ} \mathrm{C}$ in $\mathrm{Es}_{3}$ and $\mathrm{Es}_{4}$, Shengtuo area

that it can provide more reliable technical support for the comprehensive evaluation of reservoirs with hydrocarbon exploration and development potential.

2) The methodology of calculating porosity and permeability cutoffs of RIAC according to different porethroat structures has been outlined. If historical dynamic forces and their evolving history as well as types of pore throat structures are considered, the study could make activities relating to prediction of hydrocarbon distribution more accurate in an area of exploration potential.

\section{Acknowledgements}

This research has been co-funded by National Natural Science Foundation of China (Grant No. 41102058; Grant No. U1262203), the National Science and Technology Special Grant (No. 2011ZX05006-003), Shandong Natural
Science Foundation (Grant No. ZR2011DQ017) and the Fundamental Research Funds for the Central Universities (No. 12CX04001A; No. 13CX02035A; No. 13CX02036A). We thank Mr. Zhang Jingxuan from the Geological Science Research Institute of Shengli Oilfield for his help in polishing the language of this paper.

\section{References}

Bouffin $\mathrm{N}$ and Jensen J L. Efficient detection of productive intervals in oil and gas reservoirs. Journal of Canadian Petroleum Technology. 2010. 58-63

Cao Y C, Wang Y Z, Xu T Y, et al. The petrophysical parameter cutoff and controlling factors of the effective reservoir of beach and bar sandbodies of the upper part of the fourth member of the Shahejie Formation in west part of Dongying Depression. Acta Sedimentologica Sinica. 2009. 27(2): 230-237 (in Chinese)

Cobb W M and Marek F J. Net pay determination for primary and waterflood depletion mechanisms. 1998. 27-30 (SPE 48952)

Danesh A. PVT and Phase Behavior of Petroleum Reservoir Fluids. Elsevier Science. 1998. 293-300

Gao J G, Gao S X, Wang F H, et al. Characteristics of formation pressure and its influences on reservoirs of the fourth member of the Shahejie Formation in Shengtuo area of Dongying Depression. Petroleum Geology and Recovery Efficiency. 2008. 15(1): 35-38 (in Chinese)

Geng L X, Cao Y S, Yi Z W, et al. A study on petrophysical property cutoffs of sandstone reservoirs in Pucheng oil field. Petroleum Exploration and Development. 1999. 26(1): 81-83 (in Chinese)

Guo R. Supplement to determining method of cut-off value of producible reservoir. Petroleum Exploration and Development. 2004. 31(5): 140-144 (in Chinese)

Hall J E. The importance of a complete suite of logs in an old reservoir. JPT. 1983. 1178

Hao F, Zou H Y and Gong Z S. Preferential petroleum migration pathways and prediction of petroleum occurrence in sedimentary basins: A review. Petroleum Science. 2010. 7: 2-9

Hobson D G. Some Fundamentals of Petroleum Geology. London: Oxford University Press. 1954. 139-150

Jiang Y Q, Gao Y, Xu H W, et al. New method for determining cut-off parameter in hydrophilic and low permeable sandstone reservoircase of gas reservoir, Hebaochang area. Petroleum Geology and Recovery Efficiency. 2003. 24(2): 162-166 (in Chinese)

Jiao C H, Xia D D, Wang J, et al. Methods for determining the petrophysical property cutoffs of extra-low porosity and permeability sandstone reservoirs - an example from the Xishanyao Formation reservoirs in Yongjin oilfield. Oil \& Gas Geology. 2009. 30(3): 379383 (in Chinese)

Li W H, Liu Y Q and Feng Q. Reservoir characteristics and hydrocarbon accumulation regularity of the Chang 6 oil-bearing beds in the Chuankou Oil Field, Shaanxi Province. Acta Petrologica Sinica. 1998. 14(1): 117-127 (in Chinese)

Liu Z, Huang Y H, Pan G F, et al. Determination of critical properties of low porosity and permeability sandstone reservoir and its significance in petroleum geology. Acta Geologica Sinica. 2012. 86(11): 18151825 (in Chinese)

Luo X R. Understandings on dynamical studies of hydrocarbon migration and accumulation. Natural Gas Geoscience. 2008. 19(2): 149-156 (in Chinese)

Luo X R and Vasseur G. Geopressuring mechanism of organic matter cracking: Numerical Modeling. AAPG Bulletin. 1996. 80(6): 856873

MacKenzie W T. Petrophysical study of the Cardium Sand in the Pembina Field. 1975 (SPE 5541)

Nelson P H. Pore-throat sizes in sandstones, tight sandstones, and shales. 
AAPG Bulletin. 2009. 93(3): 329-340

Nelson P H and Batzle M L. Single-phase permeability. In: J. Fanchi. Petroleum Engineering Hand-book: General engineering: Richardson, Texas, Society of Petroleum Engineers. 2006. 1: 687726

Pan G F, Liu Z, Zhao S, et al. The study on lower limit of porosity for oil accumulation in Chang-8 Member, Zhenjing area, Ordos Basin. Geoscience. 2011. 25(2): 271-278 (in Chinese)

Pang X Q, Liu K Y, Ma Z Z, et al. Dynamic field division of hydrocarbon migration, accumulation and hydrocarbon enrichment rules in sedimentary basins. Acta Geologica Sinica. 2012. 86(6): 1559-1592

Qi H F. Cutoffs of gas reservoir parameters and a discussion on deep gas exploration. Natural Gas Industry. 1989. 9(5): 26-29 (in Chinese)

Rockwood S H, Lair G H and Langford B J. Reservoir volumetric parameters defined by capillary pressure studies. AIME. 1957. 210: 252-255

Shao C X, Wang Y Z and Cao Y C. Two new methods used to determine the low limits of effective reservoir physical properties and their applications - A case study on deep clastic reservoir of Palaeogene in Dongying Depression. Journal of Oil and Gas Technology. 2008. 30(2): 414-416 (in Chinese)

Song L. Study on sedimentary characteristics and physical property cutoff of the main sand bodies of Paleogene in Dongying Sag. Qingdao: China University of Petroleum (East China). 2011 (in Chinese)

Tang X Y. Volcano rock reservoir control factors and physical property lower limit in north area of Karamay. Journal of Southwest Petroleum University (Science \& Technology Edition). 2011. 33(6): 7-12 (in Chinese)

Wang C, Shao H M, Hong S X, et al. The lower limits of physical properties for deep clastic reservoirs in north Songliao Basin and its relationship with microscopic features. Petroleum Geology \& Oilfield Development in Daqing. 2007. 26(5): 18-20 (in Chinese)

Wang J, Cao Y C, Gao Y J, et al. Petrophysical parameter cutoff and controlling factors of effective reservoir of red beds sandbodies of Paleogene in Dongying Depression. Journal of China University of Petroleum (Edition of Natural Science). 2011. 35(4): 27-33 (in Chinese)

Wang X J, Zhao Y S, Xu H W, et al. Stress sensitivity and property lower limit of deliverability in the low-permeability reservoir. Oil \& Gas Geology. 2003. 24(2): 162-166 (in Chinese)

Wang Y Z and Cao Y C. Lower property limit and controls on deep effective clastic reservoirs of Paleogene in Chezhen Depression. Acta Sedimentologica Sinica. 2010. 28(4): $752-761$ (in Chinese)

Wang Y Z, Cao Y C, Song G Q, et al. Application of production test data to evaluation of the effective reservoir in deep clastic of Bonan Sag. Acta Petrolei Sinica. 2008. 29(5): 701-710 (in Chinese)

Wang Y Z, Cao Y C, Song G Q, et al. Determination of physical property lower limit of deep clastic effective reservoirs of Paleogene in Dongying Depression. Journal of China University of Petroleum (Edition of Natural Science). 2009. 33(4): 16-21 (in Chinese)

Worthington P F. The application of cut-offs in integrated reservoir studies. SPE Reservoir Evaluation and Engineering. 2008. 11(6): 968-975

Worthington P F and Cosentino L. The role of cutoffs in integrated reservoir studies. SPE Reservoir Evaluation \& Engineering. 2005 (SPE84387)

Xie G J and Jin Z J. One dimensional numerical simulation of oiltrapping process of original lentoid sand reservoir. Earth Science (Journal of China University of Geosciences). 2008. 33(1): 97-106 (in Chinese)

Zhang C, Jiang Y Q, Guo H G, et al. Determination method of matrix physical property lower limit of effective reservoirs. Natural Gas Industry. 2010. 8(2): 11-16 (in Chinese)

Zhang Y Q, Huang Z L, Gao G, et al. The lower limit values of physical properties for the Mesozoic hydrocarbon carrier beds in the Karamay-Baikouquan area and their relation with petroleum accumulation. Geological Journal of China Universities. 2008. 14(2): 250-255 (in Chinese)

Zhu G Y, Jin Q, Zhou J L, et al. Physical properties and genesis of oil in Shengtuo oilfield in Jiyang Depression. Oil \& Gas Geology. 2004. 25(1): 9-13 (in Chinese)

(Edited by Hao Jie) 